\title{
PSEUDOCYESIS: A CASE REPORT ON FALSE PREGNANCY
}

\author{
SULTANA K ${ }^{1}$, NAZNEEN R ${ }^{2}$, ARA I ${ }^{3}$
}

\begin{abstract}
:
A 37 years old woman, married for 21 years having no issue, presented with $\mathrm{H} / \mathrm{O}$ secondary amenorrhoea for 8 months with experience of having foetal movements. Her ultrasonography shows non-gravid uterus with multiple fibroids. This case report emphasized the false belief of pregnancy, known as psecdocyesis, which is an emotional and psychological condition in woman.
\end{abstract}

Key words: Pseudocyesis, false pregnancy.

J Dhaka Med Coll. 2012; 21(2) : 235-237.

\section{Introduction :}

The term pseudocyesis refers to a false sensation of being pregnant in a woman who is not. In mammals pseudocyesis is called pseudo pregnancy. It is often associated with clinical and sub-clinical signs and symptoms associated with a normal pregnancy. It is rare, occuring at a rate of 1-6 for every 22,000 births ${ }^{1}$. Though the disorder is unusual, cases of pseudocyesis have been reported in human society since ancient times, providing evidence that the phenomenon is not bound by time or culture. Hippocrates described 12 cases of Pseudocyesis in 300 B.C. The English queen Mary tudor is widely believed to have suffered from pseudocyesis ${ }^{2}$. Pseudocyesis has a psychological basis in which a woman's wish for pregnancy is essential to their identities and self esteem. Normally pseudocyesis is seen in women who desperately want to become pregnant, especially those with longstanding infertility. Basically, the treatment of pseudocyesis is to help these patient recognize the illness and to educate and counsel them ${ }^{3}$. Here, is the case of pseudocyesis in which there is the history of longstanding infertility with having fibroids in uterus.

\section{Case report:}

A 37 old housewife, married for 21 years having no issue, hailing from Bhola district was consulted at OPD of Holy Family Red Crescent Medical Hospital with history of amenorhoea for 8 month and pain in lower abdomen for 7 days. She gave the history of nausea and vomiting in her early period of amenorhoea thereafter gradual enlargment of her abdomen with the experience of foetal movements. She consulted with a village kabiraj for her childlessness for last 10 years. Though all the symptoms and signs of pregnancy were present, she did not consult for these reasons with a physician. On examination her vital signs were within normal limit. She is not anaemia and oedema was not present. Per abdominal examination revealed a swelling about 30-32 weeks size of gestation, having irregular margin, restricted in mobility and firm in consistency. No foetal parts or movements were felt. On auscultation, no foetal heart sound was heard. Ultrasonography suggested multiple fibroids of varing sizes were present in uterus, of them two fibroids were degenerated. The uterine cavity was empty and ovaries were cystic in appearance. Her serum 3 hCG was $<0.1 \mathrm{mIU} / \mathrm{L}$ and serum $\mathrm{FSH}$, serum prolactin and thyroid function were within normal limit.

\section{Operative findings:}

As the patient was infertile, she was counseled properly for myomectomy. Per operatively the uterus was hugely enlarged with multiple subserous fibroid. About 18 fibroids were removed. After proper haemostasis abdomen closed in layers. Postoperative period was uneventful.

1. Dr. Kishwar Sultana, Associate Professor, Department of Obstetrics \& Gynaecology, Holy Family Red Crescent Medical College \& Hospital, Dhaka.

2. Dr. Rumana Nazneen, Associate Professor, Department of Obstetrics \& Gynaecology, Holy Family Red Crescent Medical College \& Hospital, Dhaka.

3. Dr. Iffat Ara, Professor, Department of Obstetrics \& Gynaecology, Dhaka Medical College, Dhaka

Correspondence : Dr. Kishwar Sultana, Associate Professor, Department of Obstetrics \& Gynaecology, Holy Family Red Crescent Medical College \& Hospital, Dhaka. 


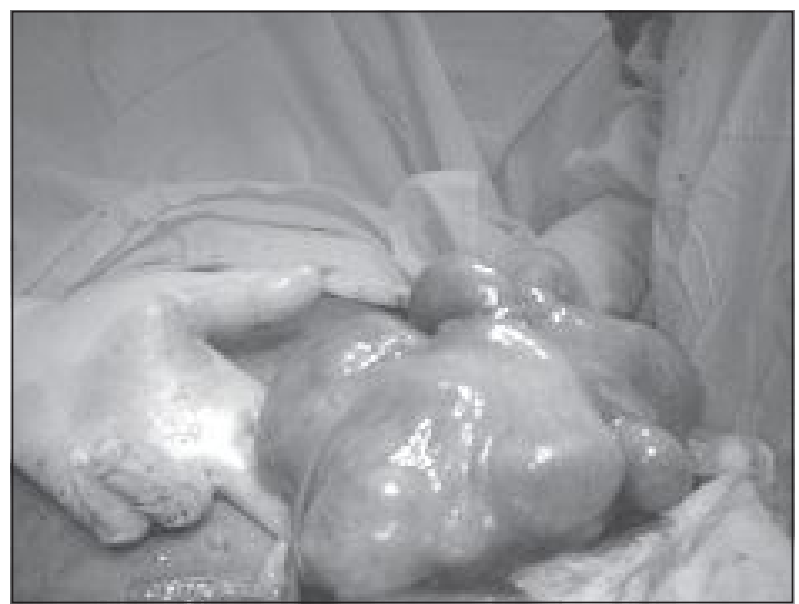

Fig.-1: Per-operative finding ofuterusmyomectomy

\section{Discussion:}

Pseudocyesis is a conversion reaction in which a psychic conflict is expressed in physical terms. It is an example how a false belief may affect physiological process ${ }^{4}$. It is a medical phenomenon in which woman experience all the symptoms of pregnancy without actually being pregnant. Those affected by this disorder exhibit amenorrhea, tender and swollen breasts, distended abdomen, morning sickness and even foetal movement ${ }^{5}$. In very rare cases, a woman may even experience labour pain and phantom delivery.

Cases of psuedocyesis have been documented since antiquity. Hippocrate described this condition around 300 B.C. Mary-I (1516 - 1558), queen of England was perhaps the most famous historical example, who believed on two occasions that she was pregnant, when she was in fact not. John Mason Good coined the term pseudocyesis from the Greek words pseudoes (false) and kyesis (pregnancy) in 1923. The symptoms of pseudocyesis are similar to the symptoms of true pregnancy and are often hard to distinguish from it. Many health care professionals can be deceived by the symptoms associated with pseudocyesis. Research shows that $18 \%$ of women with pseudocyesis were at one time diagnosed as pregnant by medical professionals. Abdominal distention is the most common physical symptoms of pseudocyesis (60-90\%). The second common physical sign of pseudocyesis is menstrual irregularity (50-90\%). Women are

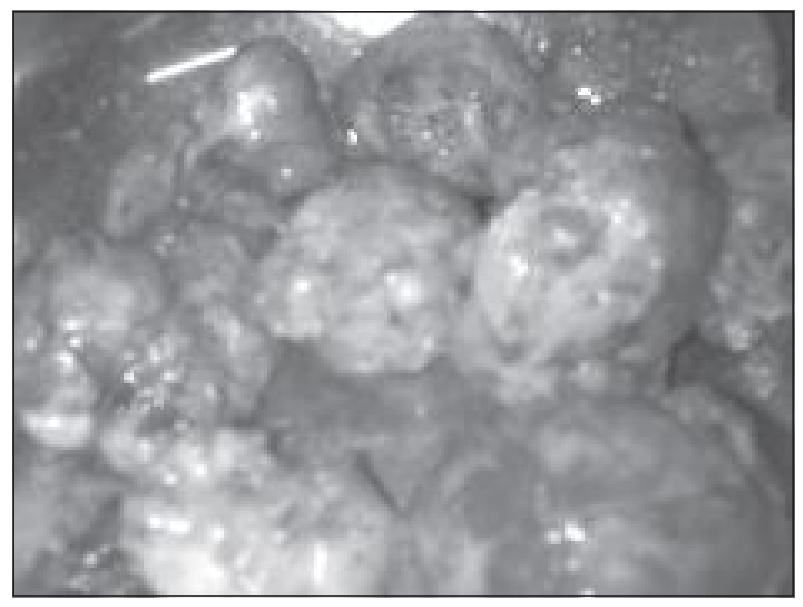

Fig.-2: Multiple fibroids after with multiple fibroids

also reported to experience the sensation of foetal movement (50-70\%), though there is no foetus. There common signs and symptoms include gastrointestinal symptoms, breast changes or secretions. The people who are most affected by pseudocyesis are women in their late 30-40 yrs of age, who have fertility problems or are desperate for a child ${ }^{6}$. Women who have suffered a miscarriage or have lost a child are also susceptible for pseudocyesis. More than tow-thirds of women who experience pseudocyesis are married and about one-third have been pregnant at least once. Generally women goining though a phantom pregnancy are emotionally unstable and may have often psychological problems. An extreme fear of becoming pregnant has also been shown as a risk factor for developing pseudopregnancy.

The exact cause of producing the symptoms and signs of pseudocyesis is not known. There are various explanation, none of which is universally accepted because of the complex involvement of cortical, hypothalamic, endocrine and psychogenic factors ${ }^{7}$. It is believed that this psychological desire or depression triggers the pituitary gland to secrete elevated hormones, mimicking the hormone changes of real pregnancy ${ }^{8}$. Because of the small number of people who have the disorder, no large scale studies have been conducted to establish a typical hormonal profile of pseudocyesis patients.

The rate of pseudocyesis has declined significantly in the past century. In the 1940s 
there was one occurrence for approximately every 250 pregnancy, this rate has since dropped to 1-6 occurrences for every 22,000 birth in united states ${ }^{9}$.

Pseudocyesis in not known to have a direct underlying physical cause and there are no general recommendations regarding treatment with medications. In some cases the patient may be given medications for symptoms like cessation of menstruation. When some patient with pseudocyesis have underlying psychological problems, they should referred to a psychotherapist. The treatment that has had the most success is demonstrating to the patient that she is not really pregnant by the use of ultrasonography or other imaging techniques However, psychotherapy is the best recourse to ensure the restoration of their mental health ${ }^{10}$.

In conclusion, the story of pseudocyesis might never be complete for we still do not fully comprehend the causes or treatment for this condition. Actually it can be said that pseudocyesis is mind over matter. In other words the women is so desperate and her desire to have a baby is so strong that her body fulfills her wish.

\section{References:}

1. All the signs of pregnancy except one; A body New York Times. www.nytimes.com /2006/12/ 05/health/ 05 pseud.html

2. Leavesley J, Biro G. What Killed Jane Austen? And other medical mysteries, marvels and mayhem. Harper Collins: Australia, 1998.

3. Upadhyay S. Pseudocyesis. J Nepal Med Assoc 2008; 47: 147-50.

4. Haessler A, Rosenthal E'MB. Psychological aspects of obstetrics and Gynecology. Current obstetric and Gynaecology diagnosis and treatment. Edited by Alan $\mathrm{H}$ Decherney and L. Nathan. $9^{\text {th }}$ edition 2003. A Lange medical book P-1085-1086

5. Marusic, Srdan, Karlovic, Dalibor, et al. Pseudocyesis: a case report. Acta Clinica Croata 2006; 45(2):

6. Paulman, Paul M. and Sadat, Abdul. "Pseudocyesis" Journal of Family Practice. May, 1990.

7. Giannini AJ, Black HR. Psychiatric, Psychogenic, and somato psychogenic Disorder Handbook. Garden City, NY. Medical Examination Publishing, 1978. p. 227-8.

8. Pseudocyesis. The Columbia Electronic Encyclopedia, 6 ${ }^{\text {th }}$ Edition. 2003.

9. Paulman PM, Sadat A. Pseudocyesis. J Family Practice. May, 1990.

10. Eilts BE. Canine Pregnancy and Pseudopregnancy." LSU School of Veterinary Medicine Online. July, 2006. 